\title{
Loving her into well-being one day at a time: Narratives of caring for daughters with eating disorders
}

\author{
Kathryn Weaver
}

Faculty of Nursing, University of New Brunswick, Fredericton, Canada

Email: kweaver@unb.ca

Received 27 September 2012; revised 13 November 2012; accepted 10 December 2012

\begin{abstract}
When a child is diagnosed with an eating disorder, parents are expected to help the child recover. Yet, parents often feel under-prepared and alone, their experiences inadequately known to healthcare professionals. The research aim was to examine the meaning to parents of caring for a child with an eating disorder. Qualitative interviews with 29 parents were analyzed and the parents' experiences were represented by a collective story of loving her into wellbeing one day at a time which consisted of two themes: Running on nerves and caring through transformational activism. Running on nerves included threads of feeling lost, traumatized, scarred, and disengaged that mitigated as parents engaged in transformational activism processes directed toward helping themselves, their child, and other parents and children. The findings illustrate the importance of hearing parents' stories in order to create supportive healing environments and to build capacity within families and health care systems.
\end{abstract}

Keywords: Eating Disorder; Parents; Narrative Analysis; Transformational Activism

\section{INTRODUCTION}

Children-particularly adolescents undergoing puberty with its dramatic physical changes and new social pressures-are often concerned about their appearance. For a number of children, that concern can lead to an eating disorder such as anorexia nervosa (self starvation) or bulimia nervosa (binge-purge cycle). Eating disorders are the third most common illness of adolescence [1-3], and although more prevalent among girls and women, boys and men are also vulnerable [4].

Generally, eating disorders involve self-critical, negative thoughts and feelings about body weight and food, and eating habits that disrupt normal body function and daily activities [5]. Eating disorders can lead to serious physical health problems including dehydration and other medical complications like heart problems, kidney failure, severe malnutrition and even death [6]. The effects are so pervasive and devastating as to require intervention via a team of trained professionals to address weight restoration and counseling needs for related issues of depression, anxiety, and perception about body size, shape, eating, and food.

Parental involvement is deemed critical to successful intervention when a child develops an eating disorder. Parents are expected to ensure the child has proper food intake and to support the medical treatment plan $[7,8]$. Despite this parental involvement, the professional literature has often conveyed parents as having contributed to their child's eating disorder. Parents may not disclose experiencing stress and guilt concerning their child's situation to avoid negative labeling. A greater understanding of the meaning to parents of caring for a child with an eating disorder will inform comprehensive treatment initiatives, enhance professional responsiveness to parents, and strengthen parental contribution to effective family-oriented care.

\section{LITERATURE REVIEW}

Using CINAHL, Psych Info, Sociological Abstracts and Medline databases and the following keywords alone and in combination: Eating disorders, anorexia, bulimia, parents, mothers, fathers, care, daughters, caring, support and recovery, 56 articles and books were located-18 which focused specifically on the parents' subjective experience of caring for a child with an eating disorder [9-26] (Table 1). This literature portrayed parents' difficulty comprehending the severity of the eating disorder $[14,20]$ and their frustration related to the child's lack of disclosure $[9,13,17,20]$ as well as to failure of primary care practitioners to initially detect the eating disorder [13] and enact compulsory treatment [21]. Parents described social isolation $[11,22,25]$, depression $[10,14,17$, $20]$, anxiety [18], burden $[16,19]$ long waiting times to receive medical attention $[11,20]$ and spending large 
Table 1. Prior research into parents' care giving experiences.

\begin{tabular}{llll}
\hline Author/Year & Research Purpose & Sample; Method & Results \\
\hline & $\begin{array}{l}\text { (a) To describe impact of } \\
\text { eating disorders on family }\end{array}$ & $\begin{array}{l}\text { (a) Described problem recognition, inaccessibility } \\
\text { of resources, care-giving efforts, and parental } \\
\text { strength. }\end{array}$ \\
$\begin{array}{lll}\text { (a) Beale, McMaster and } \\
\text { Hillege/2004 [9] }\end{array}$ & $\begin{array}{l}\text { (b) To give voice to parents } \mathrm{n}=22 \text { parents (19 M, } 3 \mathrm{~F} \text { ) } \\
\text { to enable appropriate } \\
\text { clinical decision making. }\end{array}$ & $\begin{array}{l}\text { (b) Themes: Family unification/disintegration, } \\
\text { interviews and analysis. }\end{array}$ & $\begin{array}{l}\text { inability to cope, inconsiderate comments by } \\
\text { others, social isolation and financial impacts. }\end{array}$
\end{tabular}

(c) McMaster, Beale, Hillege and Nagy/2006 [11]

2 Cook-Darrzens, Doyen, Falissard and Mouren/2005 [12]

(c) To present parents' interactions with professionals.

To determine if pattern of $n=40 \mathrm{M}, 40 \mathrm{~F}, 40$ children family functioning is and 31 siblings (France);

associated with adolescent survey responses compared anorexia nervosa (AN).

with a reference population.

To examine experiences of $\mathrm{N}=11 \mathrm{UK}$ parents $(7 \mathrm{M}, 4$ parents of a child with early onset AN.

\section{F); interpretive phenomenological analysis of qualitative interviews.}

4 Dellasega/2005 [14]

5 Gilbert, Shaw and Notar/2000 [15]

Graap, Bleich, Herbst,

6 Trostmann, Wancata and de Zwaan/2008 [16]

7 Honey and Halse/2008 [17]

Describe coping strategies of parents caring for a daughter with AN.

To provide insight, support and strategies for family caregivers.

$\mathrm{n}=26$ parents (USA); narrative approach.

To study challenges, changes and coping when $\mathrm{N}=52 \mathrm{M}$ (Canada); child diagnosed with eating quantitative and qualitative disorder.

quantitative and qualitative Family strain worse at time of initial diagnosis.

(c) Themes: Finding help, feeling shut out, engagement, being resourceful and parents not prepared to give up.

No specific pathological pattern found. Families self-described being "flexibly distant" and dissatisfied with family life.

Themes revealed extreme demand and personal challenge for parents to understand the eating disorder, its impact (dreadful monster, high stakes, living nightmare), and management.

Rich descriptions of how parents cope at home with a child with an eating disorder. To assess degree of distress with AN and 16 with BN and need for supporting (Germany); general health carers of children with AN questionnaire, burden and bulimia nervosa (BN). inventory, and carers' Needs assessment.

$\mathrm{N}=16 \mathrm{M}, 8 \mathrm{~F}(\mathrm{AU})$; parents' accounts compared to common quantitative categorizations.

\section{$\mathrm{N}=91 \mathrm{M}, 60 \mathrm{~F}(\mathrm{UK})$}

Explore and model factors associated with distress in parents of children with AN.

multiple regression. caregiving stress scale, hospital anxiety and depression scale, anorectic behaviour observation scale.

$\mathrm{N}=40$ relatives of 24

To investigate the burden of families caring for adolescents with eating disorders.

To understand parents' views of daughters' recovery from $\mathrm{AN}$.
$\mathrm{N}=10 \mathrm{M}, 8 \mathrm{~F}, 9$ recovered children and 1 sibling (Canada); grounded theory.
Most problematic were the chronic course of the illness and concerns about the child's future; most frequent need for support was counseling and professional support. Parents of children with AN reported higher scores than those with BN.

Parents define their actions differently and use coping strategies not measured by the most widely used quantitative coping instruments.

Over $70 \%$ of parents found to be anxious and $38 \%$ depressed. Parent sex and interpersonal strains accounted for $41 \%$ variance. Mothers experienced

Subjective burden reported by the key relatives of patients with AN was significantly greater than that of the key relatives of patients with BN. The relatives of AN patients scored higher for over-involvement and psychiatric symptoms than the relatives of BN patients.

Core theme "awakening" included reacting (recognizing lack of knowledge, fearing anger, and realizing it as a family problem), acting (preparing, confronting, and turning point), maintaining (accepting, making changes, and being flexible), and preventing (cluing in, building self-esteem, and educating). greater care-giving strain and distress than fathers. 


\section{Continued}

11 Tan, Hope, Stewart and Fitzpatrick/2003 [21]

12 Tierney/2005 [22]

Treasure, Murphy, Szmukler, 13 Todd, Gavan and Joyce/2001 [23]
To explore views about compulsory treatment, competence and capacity in persons with $\mathrm{AN}$.

To identify the views of parents in relation to treatment received by their children.

To examine the experience of care giving persons with AN and compare it with that of care giving person with a psychotic illness.

To gain detailed

14 Whitney, Murray, Gavan, Todd, Whitaker and Treasure/2005 [24] understanding of parents' caregiving experiences.
Winn, Perkins, Murray, Murphy and Schmidt/2004 [25] and Filippelli/2007 [26]
To understand the needs of parents and partners of persons with $\mathrm{BN}$.

To examine aspects of eating disorders as future research priorities.
$\mathrm{N}=10$ women with AN, 8 $\mathrm{M}$ and $1 \mathrm{~F}$ (UK); grounded theory.

$\mathrm{N}=8 \mathrm{M}$ and $5 \mathrm{~F}$ (UK); semi-structured, qualitative interviews.

$\mathrm{N}=71$ relatives of $55 \mathrm{UK}$

families; general health

questionnaire, experience of caregiving inventory and narrative letter writing with qualitative thematic analysis.

$\mathrm{N}=20 \mathrm{M}$ and $20 \mathrm{~F}$ (UK); qualitative analysis and computerized text analysis of written narratives.
Competence to consent to or refuse treatment found problematic because persons with AN often appear capable to make treatment decisions and yet may resist treatment. Parents justify compulsory treatment to save life.

Parents adopted stance of "hoping for the best but fearing the worst". They wanted more feedback from professionals, opportunity to discuss concerns and resources for other children.

Relatives of persons with AN experienced higher levels of difficulties and psychological distress. Themes of guilt and shame were expressed in parents' letters.

Themes: Illness perceptions, impact on family, and emotional, cognitive and behavioral responses towards the illness. Perceived AN as chronic and disabling. Blamed selves for contributing to the AN; perceived selves as helpless in promoting recovery. Mothers illustrated an intense emotional response, fathers were more cognitive and detached.

$\mathrm{N}=15$ UK parents and 5 partners of persons with $\mathrm{BN}$; Needs identified: More information, practical qualitative interviews and advice and guidance, and opportunity to talk to content analysis.

$\mathrm{N}=20$ persons with eating disorders, $37 \mathrm{M}$ and $15 \mathrm{~F}$

(Canada); research directions survey. others.

Top priorities: Treatment, family dynamics, motivation for recovery, self-esteem, weight-related comments, body image distortions, and individual psychotherapy. Parents did not identify motivation for recovery as a priority. sums of money on health insurance, hospitalization and therapists, while concerned that benefits would run out and their child unable to continue therapy [10]. Parents also reported fear, helplessness, stress, shame and guilt $[9,13,19,20,23]$; negative judgment by others [10-12]; exclusion from treatment decisions if their child was older [15]; family strain [15,26]; and marital difficulties contributing to some marriages ending in divorce [10, 11,22]. Further, parents have described being actively discouraged from taking part in their child's treatment, not having their needs addressed in clinical practice, and subsequently pulling away from professionals $[10,11,18]$.

In these and other related studies, researchers did not conclude if family stress/dysfunction was strictly an etiological factor or a consequence of the eating disorder. Findings conveying mothers as "over involved and enmeshed" and fathers as "cold and distant” [27, p. 136] with mothers viewing the family environment as "rosy" and fathers describing a more "dysfunctional” (p. 138) environment are reminiscent of 1970s observational studies which denoted families of children with anorexia nervosa as rigid, overprotective, enmeshed and unable to resolve conflicts [28,29]. Along these lines, recent work has continued to associate eating disorder development with parental overprotection [30-32], insecure attachment [33], and maternal body dissatisfaction [34]. The persisting belief of family dysfunction as an underling cause may foster tension between parents and health professionals.

Supporting greater parent involvement in treatment, Bruining et al. [35] and Russell-Mayhew and Arthur [36] found parental participation significantly decreased critical attitudes to weight and shape and enhanced eating disorder prevention. In addition, Cook-Darzens et al. [12] provided a view that families with an eating disordered child do not conform to dysfunctional patterns.

The literature conveys the need for including parents in their child's treatment and recovery. However, there remains a gap in our knowledge of the processes parents use in caring for their child with an eating disorder and the meaning they draw from these experiences. Further study of parents' experiences is recommended, specifically with the enrichment of qualitative data [37]. Such ongoing inquiry requires collaborative empowering parent-researchers relationships given the prior reported tension between parents and professionals.

\section{STUDY PURPOSE}

The research aim was to represent the voices of parents and the meanings parents draw from their experiences in caring for a child with an eating disorder which would ultimately help inform supportive care-giving interventions for children and families. Specific objectives were to 1) elicit the narratives of parents who care for a child 
with an eating disorder; 2) create a coherent collective core story through ordering the events, intentions, and nuances within the individual stories; and 3) examine the underlying processes parents use to make meaning within the larger cultural and clinical narratives of eating disorder development, treatment and recovery.

\section{DESIGN AND METHOD}

To address the objectives, a collaborative exploratory qualitative inquiry was designed with parents as story tellers and experienced registered nurses as interviewers trained to listen and respond without censure. The resulting interviews were analyzed for significant and recurring themes, with parents invited to respond to the researcher interpretation.

\subsection{Narrative Approach}

Narrative (L. narrare) describes the arranging and telling of events into stories to express understanding of intent, decisions, actions and identity [38-40] in ways that are significant and logical for the narrator and audience [41-43]. A narrative approach to research is based on assumptions that stories are the fundamental way to relate human experience [44-46], allowing people opportunity to examine, make meaning, and alter the direction of their lives [47-49]. Narrative inquiry enables access to cultural and societal influences affecting everyday life actions and choices [38,44,50]. As individuals narrate their stories, how they make sense of personal experience in relation to cultural and historical discourses and how they draw on, resist, and transform those discourses become visible [37,51].

The task of narrative analysis is to look for commonalities and differences within stories, presenting them together as a collective story containing major themes, plots, and individual threads [46]. In exploring meaning within linguistic practices and conveying the participants' unique contributions, the researcher uses reflexivity to identify personal culture, politics, and biases that possibly influence the research process and findings [50,52-54].

\subsection{Sample}

Twenty-nine English-speaking parents with experiences in caring for a child with an eating disorder were recruited via invitational letters to eating disorder support groups, newspaper advertisements and telephone follow-up. The sample included 22 mothers and 7 fathers living in an Eastern Canada province; 3 participants were of Acadian French descent and 10 comprised 5 husband-wife couples. Participants were aged 45 - 67 years and most resided in towns or cities. Their children with eating disorders were daughters who had been ill from less than 1 year to more than 33 years: 13 were diagnosed with anorexia nervosa, 10 bulimia nervosa, 3 anorexia-bulimia nervosa, and 3 eating disorders not otherwise specified. No parents of sons with eating disorders responded to the study's invitational letter and advertisement to participate.

\subsection{Data Collection}

Following institutional ethics approval, the initial qualitative interviews were conducted by registered nurses enrolled in a graduate qualitative research course offered by the PI (2007, 2009). Follow-up interviews with 5 fathers and 16 mothers were completed by the PI in 2009 and 2010. Participants were interviewed separately unless they (total of 3 ) requested their partner to be present. Interviews lasted from 24 - 117 minutes, were audio-recorded in participant preferred locations, transcribed and anonymized. For initial interviews, a schedule was developed to explore the parents' experiences in caring for their child, their understanding of the eating disorder, and their perceptions of treatment and support (see Table 2). These questions guided rather than dictated the interviews to optimize parental voice. In follow-up interviews, parents were given their individual stories, a draft summary of all stories, and opportunity to add to or clarify any aspects.

Table 2. Interview questions.

\begin{tabular}{|c|c|}
\hline 1. & $\begin{array}{l}\text { Could you tell me about your experience of caring for your } \\
\text { child with an eating disorder? }\end{array}$ \\
\hline 2. & $\begin{array}{l}\text { What does caring for a child with an eating disorder mean to } \\
\text { you? }\end{array}$ \\
\hline 3. & $\begin{array}{l}\text { Could you talk about what helped you care for your child? } \\
\text { How were specific people and events supportive to you? }\end{array}$ \\
\hline 4. & $\begin{array}{l}\text { Describe any difficulties you faced while caring for your } \\
\text { child with an eating disorder. What really did not help you? }\end{array}$ \\
\hline 5. & $\begin{array}{l}\text { Under what circumstances did you access and use the health } \\
\text { services and resources as specified on the demographic } \\
\text { information sheet? }\end{array}$ \\
\hline 6. & $\begin{array}{l}\text { How did the health care system services and resources assist } \\
\text { you? How did it hinder you caring for your child? }\end{array}$ \\
\hline 7. & $\begin{array}{l}\text { What has been the impact of the eating disorder and caring } \\
\text { for your child with an eating disorder on you and your } \\
\text { family? }\end{array}$ \\
\hline 8. & $\begin{array}{l}\text { Is there something that you would like to have happened } \\
\text { differently while caring for your child with an eating } \\
\text { disorder? }\end{array}$ \\
\hline 9. & $\begin{array}{l}\text { Describe to me any difference you see in yourself from } \\
\text { having the experience of caring for a child with an eating } \\
\text { disorder. }\end{array}$ \\
\hline 10. & $\begin{array}{l}\text { What have you learned about yourself and your needs } \\
\text { through the process of caring for your child with an eating } \\
\text { disorder? }\end{array}$ \\
\hline
\end{tabular}




\subsection{Data Analysis}

Drawing on Emden [55], Clandinin and Connelly [48] and Cortazzi [56] (education), Polkinghorne [40] (psychology) and Martin-MacDonald [53] (nursing), the interviews were analyzed to understand the parents' experiences, their time lines and perceptions. The analysis involved replaying the audio tapes, re-reading the full interview text to grasp its content and asking the following questions suggested by Cortazzi [56]: What is this about? Who are involved? What happened? Why? When and where did it happen? What happened next? What could it mean? The parents' accounts were examined for elements of time, personal and social relations, place, and voice. Time was conveyed through dynamic entwinements of past, present and future rather than linear, uni-directional clock time. Personal and social referred to participants' expressing their sense of self and relationships with others. Examining place entailed seeking out their descriptions of specific physical and topological boundaries as participants recounted feelings and emotions linked to a specific experience. To respect parental diversity and uniqueness, the voices of participants caring for their child with an eating disorder were given greater research attention than others (e.g., professionals) they referred to in their stories. The various elements of temporality, personal/social, place, and voice intersected as participants moved back and forth between past and present, reflecting on various events and their locations, and recounting their private feelings amid social interactions.

Data were sorted under descriptive codes that emerged from examination of the data (i.e., codes were not predetermined) and organized into threads, themes, individual core stories representing each parent's experiences and a synthesis of collective experiences. Threads were constructed from clustering similar data within and across the stories; themes from clustering threads. Using Emden's method [55], core stories were created from full length stories by deleting interview questions and extraneous words and content. A process of tacking [40] or searching back and forth between stories helped identify distinguishing subplots within the stories that were common to more than one story.

The mothers' and fathers' core stories were examined separately for differences. Mothers reported more often being responsible for meal preparation and supervision, scheduling medical and counseling appointments, transportation of the daughter to and from appointments, interacting with teachers, and engaging in conversations with daughters. Fathers more often disengaged, relegated care giving to mothers, acknowledged inability to understand the daughter's motivation and coped through long hours at work. Because the analytic process revealed sets of subplots common to all stories and the research intent was to understand the meaning of parents' care-giving experiences, data from both mothers' and fathers' interviews were analyzed together in this study. A separate project [57] was implemented to highlight the fathers' unique experiences as these are largely absent in the literature.

Once all subplots were identified with no new ideas emerging in the data, the subplots were grasped together into one story. This enabled what Polkinghorne calls making "individual events comprehensible by identifying the whole to which they contribute” (p. 18) [40]. Aspects of the collective story were compared with similar concepts in the mental health, care-giving and population health literature.

\subsection{Rigor and Validating with Participants}

Narrative truth is assessed by the coherence, congruence, and completeness of the subjective account of a specific experience $[53,58]$. Criteria of verisimilitude (truth-like quality), ethicality (protecting participants' rights, ensuring transparency of research decisions) and fidelity (integrity on the part of the researcher to preserve the worth and dignity of the storyteller [59]) also guided scientific rigor. The voices of all participating parents were contained in the collective core story; their words were retained and given priority over researcher interpretation to enhance the utility of the research findings to others. Quotations are identified by $\mathrm{M}$ or $\mathrm{F}$, denoting mother or father respectively, and the participant identification number; content from the interviews is given in italics Including all participants enhanced the level of trustworthiness beyond member checking [60] and adherence to rigorous research and analytical practices [40,61]. Individual core stories and a draft of the collective story were taken back to participants. Cycling the findings of the study this way added what Brantlinger [62] has termed “catalytic validity” (p. 420): Parents became energized and more aware of their common issues in caring for a child with an eating disorder. In providing opportunities for participants to review the researcher interpretation, their comments and suggestions became part of the research story and were included in the final narrative product. Participants agreed with the collective core story, adding that it offered a helpful glimpse into their own and others' experiences. "This could be given to parents when their child is first diagnosed. Then they would know what to expect and believe more in their ability to help their child" [M7].

\section{FINDINGS}

The collective story of parents' caring for a daughter with an eating disorder is called loving her into wellbeing one day at a time and contains two major themes. 
The first theme, running on nerves, is experienced as an acutely distressing emotional state of feeling lost, traumatized, scarred, and at times disengaged. The second theme, caring through transformational activism, includes respecting the daughter's autonomy, surreptitious watchfulness, intuitive reasoning, and bridging to provide support and resources as needed (Table 3).

\subsection{Loving Her into Well-Being One Day at a Time}

Parental love for their daughter and concern for her immediate and future well-being drive parents' efforts to help her become healthy and happy. "She's my child and I love her. I wanted to make sure she didn't become ill for the rest of her life" [F5]. Parents love the daughter unconditionally, despite her fluctuating health status and negative outbursts. "No matter what her state of mind, I will always be there for her" [M19, F7]. Parents believe their love for the daughter exists outside of their control, and although given freely, they do not have free choice. "You have to tell them you love them. They are really hard on themselves" [M15].

The process of loving her is time and labor intensive. "You do it one day at a time and you don't really think about it. It has to be done and there is no one else to do

Table 3. Summary of themes and threads for loving her into well-being one day at a time.

Running on nerves

Distressing emotional and behavioral responses when demand exceeds usual care-giving capacity.

\begin{tabular}{lll}
\hline Lost & $\begin{array}{l}\text { Uncertainty for how to best help the } \\
\text { daughter amid overwhelming fear for } \\
\text { her health and life }\end{array}$ \\
$\begin{array}{l}\text { Characterized } \\
\text { by feeling: }\end{array}$ & Traumatized & $\begin{array}{l}\text { Pain from the intrusion of the eating } \\
\text { disorder and its associated burden }\end{array}$ \\
& Scarred & $\begin{array}{l}\text { Negative and positive effects of } \\
\text { caring for a child with an eating } \\
\text { disorder }\end{array}$ \\
Disengaged & $\begin{array}{l}\text { Withdrawing from the daughter's } \\
\text { behaviors }\end{array}$
\end{tabular}

Caring through Transformational activism

Process of empowerment to address situational and long term learning and support needs

\begin{tabular}{|c|c|c|}
\hline \multirow{4}{*}{$\begin{array}{l}\text { Characterized } \\
\text { by actions: }\end{array}$} & $\begin{array}{l}\text { Respecting } \\
\text { her autonomy }\end{array}$ & $\begin{array}{l}\text { Providing space for the daughter to } \\
\text { acknowledge the problem and engage } \\
\text { in treatment }\end{array}$ \\
\hline & $\begin{array}{l}\text { Surreptitious } \\
\text { watchfulness }\end{array}$ & $\begin{array}{l}\text { Protecting daughter through } \\
\text { unobtrusive monitoring of her eating } \\
\text { and purging behaviors }\end{array}$ \\
\hline & $\begin{array}{l}\text { Intuitive } \\
\text { reasoning }\end{array}$ & $\begin{array}{l}\text { Attuning to the daughter's plight } \\
\text { and acting on perceptions of } \\
\text { danger }\end{array}$ \\
\hline & Bridging & $\begin{array}{l}\text { Establishing new connections for } \\
\text { parents and their daughters to } \\
\text { access resources }\end{array}$ \\
\hline
\end{tabular}

it" [M14]. Parents learn the extent of the care-giving demand as they go. "I was thinking there might be an instant fix. I felt that if somebody caught her at this time [pre-hospitalization] and fixed it, within a week she'd be back to herself. But it didn't work that way" [M11]. Indeed, parents must continuously and incrementally adjust their understanding and expectations.

It takes time for you to understand things because the information comes in bits and pieces. It's a gradual thing so the more it comes out the better you understand that it does take time. My daughter and I are probably both in the same boat right about now. Tomorrow we could be in separate boats. I guess it's just a matter trusting the process [M4].

Outcomes from loving the daughter include developing a more compassionate life philosophy. One father changed his outlook of his daughter who struggled with anorexia: "I respect her more now... She had a rough world; she could have died but she survived" [F2]. The analysis revealed that parents suffer for their child and yet they transcend their suffering, transform it into a story of strength and wisdom, and are irrevocably changed by this process.

You set your priorities differently after you go through this experience. You realize that things were not big deals before... I used to be reactive. I don't think I'm as flappable as I used to be. I am more laid back. You realize it's not worth fighting and squabbling. You see the importance society puts on this body beautiful ideal. The individual gets lost in the shuffle. Health is everything [M8].

\subsection{Running on Nerves}

From the tremendous challenge to care for the child with an eating disorder while simultaneously caring for others and self, parents enter an uncomfortable state of running on nerves. They feel lost in that they do not know what to do and who to trust for their child's immediate care. Traumatized by the effects of the eating disorder and by negative judgments of others, they are scarred. With professional advice or on their own, they may disengage from the situation.

\subsection{Lost}

Parents are initially lost alongside their child with an eating disorder and unable to find their way. They liken the experience to the child having cancer or a crushing accident, expressing terror that their daughter could die. "She was pencil thin... It was scary to think her heart could have stopped" [F2]. Being lost drains self-assurance; parents feel helpless, trapped in "a nightmare" [M1, M6, M16] of uncertainty about how to interact with the child. 'You can't just tell her Don't do it! ... You don't 
know if you are saying the right thing" [F5]. Parents want reliable information about eating disorders and resources.

What do we do? Where do we turn? It's overwhelming. It overtakes your life and turns your whole world upsidedown. It's so hard because you don't know now how to deal with it. As a parent, you would die for your child and having a child with an eating disorder means you are living in fear" [M6].

The situation is worsened as former ways of interacting with the daughter are also lost.

The relationship we'd had previously disappeared. I couldn't talk to her; we couldn't talk to each other. It was something that had taken right over her. I would lie in bed at night crying my eyes out, knowing that in the next bedroom was this bony daughter. I would sneak peaks at her, basically look over at her and try to convince myself that it wasn't as bad as it was, that maybe she had gained a little bit. But then I looked at her hands, and they were bones. And if I gave her a hug, golly! Her bones were just sticking out of her little back" [M11].

Exhausting their usual methods of what they could do on their own, parents turn to health professionals. "I am not going to allow you [my daughter] to sit and starve" [M5].

General practitioners are most often consulted first. Confused and disgruntled by failure of professionals to recognize the eating disorder in initial visits or to attribute it to something else (e.g., Reynaud's disease, athletic overtraining), particularly if this results in treatment delay, parents want answers to manage the child's care. “Nobody seemed able to tell you. They said don't talk about eating, ignore it. Well hello! Twenty-four hours a day, try to ignore it!” [M11].

\subsection{Traumatized}

For one mother, caring for her child with an eating disorder was so traumatic she compared it to hell.

It's hell for the person that is going through it, and the people who are trying to care for them. You feel so bad for the person going through the hell. You hurt for them. You are struggling because you are going through the hell yourself [M6].

Parents perceive the eating disorder as a "disease of the soul" [M13] that stops the child from being "the daughter I once knew" [M7] and controls the child to the point of her acting "just like a zombie" [F1]. The parents' pain is worsened as the entire family is affected. Vacations and social activities are cancelled. "We could not have other families in to eat a meal. If you have one member sitting there not eating, it is not fair to bring somebody in to that kind of tension" [M21]. Directing much energy toward the daughter with the eating disor- der means that other children are "put on the back burner" [M9]. These children may need therapeutic intervention as well.

My youngest daughter needs to speak to someone. One day when she had a friend here, they found containers of [her sister's] vomit. You can imagine how horrifying, embarrassing and terrible that was for my youngest daughter. She said "Mom, I don't even want to bring my friends here” [M17].

Parents are further traumatized if blamed for the child's illness. "She said that she had an eating disorder and it was caused by me, and her psychologist had told her it was best to stay away from me. All the blame went on $m e$ " [M12]. Another mother was blamed by the counselor for not eating properly when pregnant "causing [her daughter to be] starving in the womb” [M16]. Fathers reported not being singled out and blamed by professionals. In this study, either the mother is solely blamed, or the parents as a unit are blamed (e.g., "Our daughter was told that we were a hindrance rather than a help" [M21]). One mother did not disclose marital difficulties to the treatment team because she worried "the [treatment] team would shift focus from my daughter to my husband and me while she [daughter] needed their full attention” [M15].

Parents with younger children are relieved when their child is admitted to a pediatric unit. They do not think it appropriate for their child to be on a psychiatry unit Parents of older children admitted to psychiatry units report feeling excluded from treatment. "Because she was technically an adult, not a child, they didn't have to discuss anything with us and they really didn't; that was where you felt frustrated because you felt out of the loop" [M20]. Some parents described sending older daughters outside of the province to receive treatment at considerable financial cost.

\subsection{Disengaged}

Appalled by the eating disorder, parents try to disengage from the associated behaviors (e.g., angry outbursts, binging and secretive actions).

She'd been a perfectly normal child, eating perfectly normal meals at perfectly normal times. And here she was, coming down at midnight and cooking up huge meals and then going up to her room and eating them. It was sort of off-putting [F5].

Parents disengage out of fear of making the situation worse, their need to reflectively step back to plan their next action, and lack of practical knowledge. "I didn't really understand, not having had to face this with my other children. So I took a back seat, watching what developed" [F5]. Parents may also disengage in response to recommendations by the treatment team and to allow the 
daughter space. Under these conditions, they are praised.

Support by families, friends and the treatment team influences parental engagement with their daughter. According to one father, "There were only 3 - 4 people I could connect with... I don't think I ever talked to my brothers and sisters about it. I wish I could have. It would have helped me to reach out" [F2]. Unsupported parents report "walking on egg shells" [F5, M4] and "tread(ing) softly" [M19] so as to not antagonize the healthcare team or the daughter.

\subsection{Scarred}

The emotional, physical, social and financial burden of caring for a child with an eating disorder taxes parents beyond what some can safely give, resulting in scarring. "Visiting her in the hospital 6 out of 7 nights for 1.5 years... meet(ing) with the team... certainly wore me out. I developed health issues myself' [M8]. In addition to decline in personal health, negative scars manifest as self blame, unresolved guilt and sense of inadequacy. Parents are haunted by perceptions that their own dieting, exercising and appearance-focused behaviors have negatively affected the daughter. For example, M13 blamed herself because "I was a pretty woman in my youth with everything in my life centered on being beautiful. You wonder how much you communicate that to your children. How much did I contribute?”

Scarring continues even as the child recovers because parents believe the eating disorder could return.

I learned that you can never rest easy that it is over. If you do, that demon can come back in your life again. The stress of living with an eating disorder and the stress of living with some of the conditions that go along with it don't go away [M13].

Positive scarring may accompany the negative scarring and includes closeness, growth, new learning, and resilience. Parents perceive as positive the experience of the family being "brought closer together... and learn (ing) together” [M7, F3]. In recounting their experiences, the resulting positive scarring is highly prized by parents.

As a character building experience, it was wonderful. There was heartbreak but also growth beyond expectations. Character is forged at the worst of times-not at the best. You get to be real human. You look at people differently, with greater compassion [M13].

Correspondingly, priorities and attitudes change. "What I thought was important before [a clean house] is no longer" [M8].

\subsection{Caring through Transformational Activism}

In caring for their child with an eating disorder, parents confront "unprecedented ups and downs many times in a single day" [M3]. Because the situation is often volatile (e.g., daughters lash out), parents direct their care toward surreptitious watchfulness and using intuitive reasoning to predict the daughter's responses, while respecting the daughter's autonomy and bridging gaps with support/ resources.

These parental behaviors are intended as meaningful, sustainable support processes for their daughters and other family members. Through such actions, parents transform on the inside, their experiential accounts serendipitously matching descriptions of transformational activism, an idea exemplified in such activities as global peacekeeping. Transformational activism helps individuals and territories achieve well-being, power-sharing, support, and social development [63,64]. Change is inspired through setting an example to others [65], garnering practical and political support from the local community [66], and downplaying authoritarian values [67]. Transformational activism does not require prior experience; parents in this study describe having gone about their lives comfortably and unaware of the issue of eating disorders until their child is affected.

I was always very smug that I had two very healthy, intelligent daughters who did very well in school and were on their path to achieving what they wanted in life. I guess maybe you shouldn't be so smug because you just never know when something's going to come out of left field and hit you in the face [M20].

\subsection{Respecting Her Autonomy}

Most parents believe the child must reach "bottom [M5],” acknowledge the problem and ask for help before treatment can be successful. Consequently, parents feel "at a standstill" [M17] until the child is willing to cooperate with treatment. Parents try to bring the bottom closer to the child by pointing out negative health consequences (e.g., possibility of collapsing).

I'd be right in her face literally screaming "Do you want to die because that's where you're headed? You have to eat or you're going to die. I'm saying your heart can stop. You're dehydrated. So you're either going to eat now or we're going to the hospital." It's horrible to stand in front of your daughter and ask her if she wants to die [M20].

Parents later identify that such "scare tactics" [M11, F 6] are ineffective. Although the process is frustrating and slow, respecting the child's autonomy helps parents develop a broader, holistic understanding beyond the treatment team's expectations.

The psychologist said my daughter has to realize she has a problem and she has to realize how to deal with it. She has to learn to deal with this. She has to choose to have treatment. She's 14 now. I think she also has to learn to deal with peer pressure as it's not only her that's 
involved in this [M17].

In respecting their daughter's autonomy even when she has not exhibited recovery behaviors after years of having the eating disorder, parents acknowledge "moving on with life" [M12]. Parents who are not living in the same household as their daughters, or less emotionally caught up in their daughter's events continue to seek understanding and encourage their daughter to recognize her need for seeking help.

\subsection{Surreptitious Watchfulness}

Parents watch over their daughters, all the while trying to conceal this monitoring to limit the daughter's reaction. Parents report the need to become "very observant about what they're eating or not eating" and to "listen for the cues" (e.g. excessive bathroom use, hidden food).

You become so watchful which drives her crazy because she doesn't want to be looked at like she's under a microscope. You have to watch your tone of voice because she would take it as "there's a deeper meaning, why are you asking me that?" or "don't you believe that I'm doing what I should?" I was just trying to make sure she ate enough each day to stay alive (M20).

In monitoring daughters with eating disorders, parents are aware that the daughter may lack knowledge of the danger she is in. "I feared for her life as she had suicide thoughts. I didn't let her go anywhere that I wasn't right there as a shadow" [M21]. Such watchfulness is filled with emotional pain. "Mentally it's hard to just observe, to live with somebody and just see them basically killing themselves" [M22]. Parents say they would like to relinquish responsibility for their child's care to professionals; however, they do not do so because they believe they are better able to act in their child's best interests.

Many nights I slept on the floor by her bed because I was scared she was going to convulse. I could take her pulse at night and it was skipping all over everywhere. There were times when it was so slow and faint. My concern was that if I took her in [to the ER], they would take care of just her physical being. That isn't the root of the issue, and that would make her more resistant to treatment later [M21].

Parental watchfulness occurs regardless of the child's age or living arrangement. "It's engrained in me that I' $m$ the mother and she's the child. It's always going to be me taking care of her. She has a good job, but still that sense of mother and child pervades" [M4]. She continued with "I think what we're starting to develop in the last couple of months is more of a relationship between two adults."

Parents watch over their daughters with eating disorders to also protect other family members including younger siblings and grandchildren.
I worry about her three daughters because she constantly talks about what you should and shouldn't eat, watch your weight, don't get fat. Even if she's having an ice cream cone she'll say "oh I shouldn't be eating this". It's her whole focus in life and the kids are bound to pick that up [M9].

\subsection{Intuitive Reasoning}

Attuned to the dangers of the eating disorder, parents find themselves acting on their gut feelings and perceptions in the absence of concrete evidence.

I couldn't put my finger on exactly what was wrong. But I was very afraid she might die. Of course she tried to convince me she was fine. But the nagging concern made me call the doctor. The ECG showed heart block. She could easily have died [M2].

Parents read books, watch television programs, peruse the internet, and talk to others (lay and professional) who have experience with eating disorders. They ask for "more information, more classes, more awareness, more compassion" [M18]. They allocate much time, energy, and financial resources toward discovering "answers" that explain their child's eating disorder [F1, F4, F7, M21].

We have four children and they were all raised the same, treated the same and equally. It just happened to her. I am not sure why some children do not internalize the nurturing they get. She seemed like a normal happy little girl [M15].

Although parents may never receive concrete answers, they eventually arrive at a place of understanding that enables them to manage the negative scarring of self blame and guilt.

She was a little chunky in junior high. Kids can be cruel and so by the time she got to grade 10, I think she just decided she wasn't happy and she was going to make herself happy... Once she lost all the weight, she looked like a model and people just, especially if they hadn't seen her in awhile, would be like "Wow look at you what have you done to yourself!" How as a mother can you counter that? [M9].

\subsection{Bridging}

Parents intervene to secure resources and facilitate change, often bridging new connections for self and the daughter who "needed treatment because she was fading away to nothing in front of us" [M16]. Facing a lack of services in their communities, two mothers of this study interacted with schools, mental health clinics, and healthcare professionals to establish support groups for their daughters, other teenaged girls and parents. Bridging improves the daughter's access to resources, enhances the responsiveness of the larger social system and pro- 
vides social support not only for the child but also for the parents.

I requested my religious organization to form a healing group. Not for my daughter because she was in the hospital-but for me. We (this group) all talked about it and we shared stories... That really meant a lot because in a way it was a secret. And yet, if it's too much of a secret you don't get the support you need. The group was quite big and kept supporting my everyday interactions [M10].

\section{DISCUSSION AND IMPLICATIONS}

Based on interviews with mothers and fathers caring for a child with an eating disorder, the parents of this study are represented as dealing with overwhelming experiences that challenge their moral being and self worth as care-givers. They have felt lost, traumatized, disengaged and scarred: the experience of running on nerves has depleted and frightened them. Only their deep love for the daughter enables growth and action as they blend this love with ongoing practical knowledge of what the situation requires. Several salient issues have emerged from the results.

First, in spite of their intensely difficult experiences, parents were able to sustain efforts to help their daughters, other children, and other parents. The strengths, determination and resilience of parents are highlighted, a finding that is also documented by Beale et al. [9] and Sharkey-Orgnero [20]. The attribution of parental efforts to love for their daughter is however not explicitly described in prior research.

Second, the parents want greater communication with caring, knowledgeable professionals who are able to intervene effectively. When early signs of the daughter's eating disorder are missed, unnecessary delays in starting treatment increase parental fear, anxiety, and uncertainty. This concern of parents is consistent with previous research suggesting that primary care practitioners may often overlook eating disorders [12]. Further, this study's finding of reduced parental ability to collaborate with the health care team related to being negatively treated (e.g., blamed, excluded from meetings) underscores the need for what Kakkad [68] refers to as the complexity required for ethical professional practice. Professional education must socialize practitioners to recognize and promptly act during the initial stage of the eating disorder and to welcome parental input into team decision making.

Third, parents want reliable information and appropriate resources. Unique to this study, parents wanted strategies for helping them discuss the topic of treatment with their child. Without such professional guidance, parents attempted to motivate the daughter toward treatment by extolling the health risks of the eating disorder, a strategy which parents evaluated as ineffective and as serving to distance the daughter from them. The parents requested acceptable treatment for their child of any age. This study found that parents of older children admitted to psychiatry units encountered greater difficulty participating in care and treatment than parents of younger daughters admitted to pediatrics units. The finding that parents of older children are typically excluded from treatment decisions and want greater opportunity for involvement is consistent with previous research [15].

Fourth, mothers and fathers of this study questioned if familial transmission of over concern with weight and dieting behavior contributed to their child's eating disorder. Previous research [e.g., 34] focused mainly on the mother-daughter dyad was based on assumptions that the mother is the primary role model for daughters' attitudes toward dieting, weight and shape. The findings of this study point to the need for body image issues to be discussed with both parents and for further research to explore the role of parental transmission of unhealthy body image concerns including that of fathers to daughters.

Finally, the findings convey that parents, particularly mothers, continue to be blamed by professionals for the development of the child's eating disorder. Such tendency to blame parents was found to hinder the parent-professional therapeutic alliance, add to the parents' sense of inadequacy, and prevent the family-as-resource approach (i.e., an approach of involving families in positive ways through capitalizing on their strengths and abilities [68]). This study found that fear of losing the treatment team's effort discouraged one mother from disclosing marital discord. Further, this mother's portrayal of an overly pleasant picture of family environment to avoid being blamed and prevent attention directed away from the child with the eating disorder may be consistent with the phenomenon of discordant perceptions among family members reported by Dancyger, Fornari, Scionti, Wisotsky and Sunday [27]. However, in the Dancyger et al. study, the rationale behind the mothers' rosy evaluations of family environment was not explored. It is possible that other parents may also be protecting treatment attention to the child with the eating disorder. In light of this, it is sensible to follow the recommendations of Espina, Ochoa, Alda and Orteg [69] and Guttman and Laporte [70] for promoting solution-focused rather than fault-finding interventions. The implication is that professionals accept each family member's perception as constituting a more informed truth and not pathologize the family's ways of functioning.

\section{FURTHER DIRECTIONS}

Given that no parents of sons with eating disorders responded to the study's invitational letter, these perspec- 
tives are not available. Currently, it is estimated that $5 \%$ to $15 \%$ of those in treatment for anorexia and bulimia are male [6]; however, this estimate may be low since males are less likely to seek help for an eating disorder [71] or be diagnosed [72]. Future research could explore parental experiences with sons to identify aspects of the phenomenon that are specific to sons, as well as aspects that are more universal.

The parents of this study were Caucasian, fluent in the English language, and of middle class income. An area requiring further study is differing care-giving perspectives arising from variations in ethnicity and social class. For example, Becker, Franko, Speck and Herzog [73] found that ethnic minority participants with eating and weight concerns were significantly less likely than nonminority participants to have been asked by a physician about eating disorder symptoms. Research exploring cultural differences in caring for children with eating disorders is needed to balance and extend this study's Western, moderately affluent perspective.

Parents of this study wanted to be included in treatment team decision making; to contribute unique knowledge of their child's experiences, strengths, struggles, and pre-eating disorder disposition; and to have their child be the focus of treatment. Such expectation for professional responsiveness aligns with the narrative medicine approach put forward by Rita Charon [74] wherein professionals actively enter the relational space with their clients, hear their stories, are moved by their plight, and are compelled to help. Parent-expressed needs for strategies to help them approach and successfully discuss help seeking with their child also warrants investigation.

\section{CONCLUSION}

The findings of this study reveal the deep meaning of parental love as the active ingredient in transforming the parents' pain and suffering from being lost, traumatized, disengaged and scarred into practical knowledge and action that eventually serve to strengthen parents, daughters, other families, and communities. The structuring of parental efforts to watch over their children of all ages, effectively support the child through mobilizing resources, respecting the daughter's autonomy when possible and taking critical (life saving) action when necessary is a type of transformational activism. Parents' need for greater self-education, social support, and inclusion in treatment team decision making are emphasized. The unique contribution of this research is the finding that parents develop the knowledge and skills to help themselves regardless of their daughter's recovery progress and thus may serve as resources for helping their child, other parents, and healthcare providers. These parents' narratives must be brought forward to help inform re- sponsive care and to stand alongside the dominant social and clinical narratives that include parental blame. These parents are running on nerves, tired of being lost, traumatized, scarred, and disengaged. We need to hear and support them toward transformational activism.

\section{REFERENCES}

[1] Jones, J.M., Bennett, S., Olmsted, M.P., Lawson, M.L. and Rodin, G. (2002) Disordered eating attitudes and behaviours in teenaged girls: A school-based study. Canadian Medical Association Journal, 165, 547-552.

[2] Leichner, P. (2002) Disordered eating attitudes among Canadian teenagers. Canadian Medical Association Journal, 166, 707.

[3] Fichter, M.M., Quadflieg, N. and Hedlung, S. (2006) Twelve years course and outcome predictors of anorexia nervosa. International Journal of Eating Disorders, 39, 87-100. doi:10.1002/eat.20215

[4] Jonat, L.M. and Birmingham, C.L. (2004) Disordered eating attitudes and behaviours in the high-school students of a rural Canadian community. Eating and Weight Disorders, 9, 285-289.

[5] Becker, A.E., Eddy, K.T. and Perloe, A. (2009) Clarifying criteria for cognitive signs and symptoms for eating disorders in DSM-V. International Journal of Eating Disorders, 42, 611-619. doi:10.1002/eat.20723

[6] Public Health Agency of Canada (2011) The chief public health officer's report on the state of public health in Canada, 2011. Chapter 3: The Health and well-being of Canadian youth and young adults.

http://www.phac-aspc.gc.ca/cphorsphc-respcacsp/2011/p df/cpho-resp-2011-eng.pdf

[7] Lask, B. (2000) Overview of management. In: Lask, B. and Bryant-Waugh, R., Eds., Anorexia Nervosa and Related Eating Disorders in Childhood and Adolescence, 2nd Edition, Psychology Press, Hove, 167-185.

[8] Lock, J. and Le Grange, D. (2001) Can family-base treatment of anorexia nervosa be manualized? Journal of Psychotherapy Practical Research, 10, 253-261.

[9] Beale, B., McMaster, R. and Hillege, S. (2005) Eating disorders: A qualitative analysis of parent's journey. Contemporary Nurse, 18, 124-132. doi:10.5172/conu.18.1-2.124

[10] Hillege, S., Beale, B. and McMaster, R. (2006) Impact of eating disorders on family life: Individual parent's stories. Journal of Clinical Nursing, 14, 1016-1022. doi:10.1111/j.1365-2702.2006.01367.x

[11] McMaster, R., Beale, B., Hillege, S. and Nagy, S. (2004) The parent experience of eating disorders: Interactions with health professionals. International Journal of Mental Health Nursing, 13, 67-73. doi:10.1111/j.1447-0349.2004.00310.x

[12] Cook-Darrzens, S., Doyen, C., Falissard, B. and Mouren, M.-C. (2005) Self-perceived family functioning in 40 French families of anorexic adolescents: Implications for therapy. European Eating Disorders Review, 13, 223-236. doi:10.1002/erv.628 
[13] Cottee-Lane, D., Pistang, N. and Bryant-Waugh, R. (2004) Childhood onset anorexia nervosa: The experience of parents. European Eating Disorders Review, 12, 169-177. doi:10.1002/erv.560

[14] Dellasega, C. (2005) The starving family: Caregiving mothers and fathers share their eating disorder wisdom. Champion Press, Fredonia.

[15] Gilbert, A.A., Shaw, S.M. and Notar, M.K. (2000) The impact of eating disorders on family relationships. Eating Disorders, 8, 331-345. doi:10.1080/10640260008251240

[16] Graap, H., Bleich, S., Herbst, F., Trostmann, Y., Wancata, J. and de Zwaan, M. (2008) The needs of carers of patients with anorexia nervosa and bulimia nervosa. European Eating Disorders Review, 16, 21-29. doi:10.1002/erv.804

[17] Honey, A. and Halse, C. (2006) The specifics of coping: Parents of daughters with anorexia nervosa. Qualitative Health Research, 16, 611-629. doi:10.1177/1049732305285511

[18] Kyriacou, O., Treasure, J. and Schmidt, U. (2008) Understanding how parents cope with living with someone with anorexia nervosa: Modeling the factors that are associated with carer distress. International Journal of Eating Disorders, 41, 233-242. doi:10.1002/eat.20488

[19] Santonastaso, P., Saccon D. and Favaro, A. (1997) Burden and psychiatric symptoms on key relatives of patients with eating disorders: A preliminary study. Eating and Weight Disorders, 2, 44-48.

[20] Sharkey-Orgnero, M. (1999) Anorexia nervosa: A qualitative analysis of parents' perspectives on recovery. Eating Disorders, 7, 123-141. doi:10.1080/10640269908251191

[21] Tan, J., Hope, T., Stewart, A. and Fitzpatrick, R. (2003) Control and compulsory treatment in anorexia nervosa: The views of patients and parents. International Journal of Law and Psychiatry, 26, 627-645. doi:10.1016/j.ijlp.2003.09.009

[22] Tierney, S. (2005) The treatment of adolescent anorexia nervosa: A qualitative study of the views of parents. Eating Disorders, 13, 369-379. doi:10.1080/10640260591005254

[23] Treasure, J., Murphy, T., Szmukler, G., Todd, G., Gavan, K. and Joyce, J. (2001) The experience of care giving for severe mental illness: A comparison between anorexia nervosa and psychosis. Social Psychiatry Psychiatric Epidemiology, 36, 343-347. doi:10.1007/s001270170039

[24] Whitney, J., Murray, J., Gavan, K., Todd, G., Whitaker, W. and Treasure, J. (2005) Experience of caring for someone with anorexia nervosa: Qualitative study. British Journal of Psychiatry, 187, 444-449. doi:10.1192/bjp.187.5.444

[25] Winn, S., Perkins, S., Murray, J., Murphy, R. and Schmidt, U. (2004) A qualitative study of the experience of caring for a person with bulimia nervosa. Part 2: Carers' needs and experiences of services and other support. International Journal of Eating Disorders, 36, 269-279. doi:10.1002/eat.20068

[26] Witton, N., Leichner, P., Sandhu-Sahota, P. and Filippelli,
D. (2007) The research directions survey: Patient and parent perspectives of eating disorder research. Eating Disorders, 15, 205-216. doi:10.1080/10640260701323466

[27] Dancyger, I., Fornari, V., Scionti, L., Wisotsky, W. and Sunday, S. (2005). Do daughters with eating disorders agree with their parents' perception of family functioning? Comprehensive Psychiatry, 46, 135-139. doi:10.1016/j.comppsych.2004.07.024

[28] Minuchin, S., Rosman, B.L. and Baker, L. (1978) Psychosomatic families: Anorexia nervosa in context. Harvard University Press, Cambridge.

[29] Selvini-Palazzoli, M. (1978) Self-starvation: From individual to family therapy in the treatment of anorexia nervosa. Jason Aronson, New York.

[30] Allen, S.T. (2000) Attachment status, affect regulation, and behavioral control in young adults. Ph.D. Thesis. University of Connecticut, Storrs. http://digitalcommons.uconn.edu/dissertations

[31] Evans, L. and Wertheim, E. (2005) Attachment styles in adult intimate relationships: Comparing women with bulimia nervosa symptoms, women with depression and women with no clinical symptoms. European Eating Disorders Review, 13, 285-293. doi:10.1002/erv.621

[32] Meyer, C. and Gillings, K. (2004) Parental bonding and bulimic psychopathology: The mediating role of mistrust/abuse beliefs. International Journal of Eating Disorders, 35, 229-233. doi:10.1002/eat.10236

[33] Tereno, S., Soares, I., Martins, C., Celani, M. and Sampaio, D. (2008) Attachment styles, memories of parental rearing and therapeutic bond: A study with eating disordered patients, their parents and therapists. European Eating Disorders Review, 16, 49-58. doi:10.1002/erv.801

[34] Benninghoven, D., Tetch, N., Kunzendorf, S. and Jantschek, G. (2007) Body image in patients with eating disorders and their mothers, and the role of family functioning. Comprehensive Psychiatry, 48, 118-123. doi:10.1016/j.comppsych.2006.08.003

[35] Bruning Brown, J., Winzelberg, J., Abascal, L. and Barr Taylor, C. (2004) An evaluation of an internet-delivered eating disorder prevention program for adolescents and their parents. Journal of Adolescent Health, 35, 290-296. doi:10.1016/j.jadohealth.2003.10.010

[36] Russell-Mayhew, S. and Arthur, N. (2007) Targeting students, teachers and parents in a wellness-based prevention program in schools. Eating Disorders, 15, 159-181. doi:10.1080/10640260701190709

[37] Whitney, J., Currin, L., Murray, J. and Treasure, J. (2012) Family work in anorexia nervosa: A qualitative study of carers' experiences of two methods of family intervention. European Eating Disorder Review, 20, 132-141 doi:10.1002/erv.1077

[38] Chase, S.E. (2000) Narrative inquiry: Multiple lenses, approaches, voices. In: Denzin, N.K. and Lincoln, Y.S., Eds., Handbook of Qualitative Research, 2nd Edition, Sage, Thousand Oaks, 651-679.

[39] Kelly, T. and Howie, L. (2007) Working with stories in nursing research: Procedures used in narrative analysis. International Journal of Mental Health Nursing, 16, 136- 


\section{4. doi:10.1111/j.1447-0349.2007.00457.x}

[40] Polkinghorne, D. (1988) Narrative knowing and the human sciences, University of New York Press, Albany.

[41] Bailey, P.H. and Tilley, S. (2002) Storytelling and the interpretation of meaning in qualitative research. Journal of Advanced Nursing, 38, 574-583. doi:10.1046/j.1365-2648.2000.02224.x

[42] Bruner, J. (1987) Life as narrative. Social Research, 54, 11-32.

[43] Denzin, N.K. (1989) Interpretive interactionism. Sage, Newbury Park.

[44] Clandinin, D.J. (2007) Handbook of narrative inquiry: Mapping a methodology. Sage, Thousand Oaks.

[45] Joesphsson, S., Asaba, E., Jonsson, H. and Alsaker, S. (2006) Creativity and order in communication: Implications from philosophy to narrative research concerning human occupation. Scandinavian Journal of Occupational Therapy, 13, 86-93. doi:10.1080/11038120600691116

[46] McCance, T.V., McKenna, H.P. and Boore, J.R. P. (2001) Exploring caring using narrative methodology: An analysis of the approach. Journal of Advanced Nursing, 33, 350-356. doi:10.1046/j.1365-2648.2001.01671.x

[47] Bruner, J. (1991) The narrative construction of reality. Critical Inquiry, 18, 1-21. doi:10.1086/448619

[48] Clandinin, D.J. and Connelly, F.M. (2000) Narrative inquiry: Experience and story in qualitative research. JosseyBass, San Francisco.

[49] Weber, Z., Rowling, L. and Scanlon, L. (2007) “It’s like... a confronting issue": Life-changing narratives of young people. Qualitative Health Research, 17, 945-953. doi:10.1177/1049732307302011

[50] Bleakley, A. (2005) Stories as data, data as stories: Making sense of narrative inquiry in clinical education. $\mathrm{Me}$ dical Education, 39, 534-540. doi:10.1111/j.1365-2929.2005.02126.x

[51] Overcash, J.A. (2004) Narrative research: A viable methodology for clinical nursing. Nursing Forum, 39, 15-22. doi:10.1111/j.0029-6473.2004.00015.x

[52] Eaves, Y. and Kahn, D. (2000) Coming to terms with perceived danger: A researcher's narrative. Journal of Holistic Nursing, 18, 27-45. doi:10.1177/089801010001800105

[53] Martin-McDonald, K. (1999) Once upon a time... narratives and research. Contemporary Nurse, 8, 221-226. doi:10.5172/conu.1999.8.1.221

[54] Owens, J. (2007) Liberating voices through narrative methods: The case for an interpretive research approach. Disability and Society, 22, 299-313. doi:10.1080/09687590701259617

[55] Emden, C. (1998) Conducting a narrative analysis. Collegian, 5, 34-39. doi:10.1016/S1322-7696(08)60299-1

[56] Cortazzi, M. (1993) Narrative analysis. Routledge Palmer, London.

[57] Trecartin, K. (2010) Projecting fathers voices: The experiences and perspectives of fathers caring for a child with an eating disorder. Master Thesis, University of New Brunswick, Fredericton.

[58] Duffy, M. (2007) Narrative inquiry: The method. In: Munhall, P.L. Ed., Nursing Research: A Qualitative Perspective, 4th Edition, Jones and Bartlett, Sudbury, 401-421.

[59] Blumenfeld-Jones, D. (1995) Fidelity as a criterion for practicing and evaluating narrative inquiry. Qualitative Studies in Education, 8, 25-35.

doi:10.1080/0951839950080104

[60] Lincoln, Y. and Guba, E. (1985) Naturalistic Inquiry. Sage, Beverly Hills.

[61] Guba, E. and Lincoln, Y. (1989) Fourth generation evaluation. Sage, Newbury Park.

[62] Brantlinger, B.E. (1999) Inward gaze and activism as moral next steps in inquiry. Anthropology and Education Quarterly, 30, 413-429. doi:10.1525/aeq.1999.30.4.413

[63] Walls, D.S. (1993) The activist's almanac: The concerned citizen's guide to the leading advocacy organizations in America. Simon and Schuster, New York.

[64] Zisk, B.H. (1994) The politics of transformation: Local activism in the peace and environmental movements. Praege, Westport.

[65] Reimer Kirkham, S., Van Hofwegen, L. and Hoe Harwood, C. (2005) Narratives of social justice: Learning in innovative clinical settings. International Journal of Nursing Education Scholarship, 2.

http://www.bepress.com/ijnes/vol2/iss1/art28 doi:10.2202/1548-923X.1166

[66] Hunt, K. (2009) Rethinking activism: Lessons from the history of women's politics. Parliamentary Affairs, 62, 211-226. doi:10.1093/pa/gsn052

[67] Kakkad, D. (2005) A new ethical praxis: Psychologists' emerging responsibilities in issues of social justice. Ethics and Behavior, 15, 293-308. doi:10.1207/s15327019eb1504_2

[68] Lock, J., le Grange, D., Agars, W.S. and Dare, C. (2001) Treatment manual for anorexia nervosa. Guilford Press, New York.

[69] Espina, A., Ochoa de Alda, I. and Ortego, A. (2003) Dyadic adjustment in parents of daughters with an eating disorder. European Eating Disorder Review, 11, 349-362. doi:10.1002/erv.530

[70] Guttman, H.A. and Laporte, L. (2002) Family members' retrospective perceptions of intrafamilial relationships. Contemporary Family Therapy, 24, 505-521. doi:10.1023/A:1019871417951

[71] Hay, P.J., Loukas, A. and Philpott, H. (2005) Prevalence and characteristics of men with eating disorders in primary care: How do they compare to women and what features may aid in identification? Primary Care \& Community Psychiatry, 10, 1-6. doi:10.1185/135525705X40346

[72] Darcy, A.M., et al. (2011) The eating disorders examination in adolescent males with anorexia nervosa: How does it compare to adolescent females? International Journal of Eating Disorders, 45, 110-114. doi:10.1002/eat.20896 
[73] Becker, A., Franko, D., Speck, A. and Herzog, D. (2003) Ethnicity and differential access to care for eating disorder symptoms. International Journal of Eating Disorders, 33, 205-212. doi:10.1002/eat.10129

[74] Charon, R. (2001) Narrative medicine: A model for em- pathy, reflection. Journal of the American Medical Association, 286, 1897-1902.

http://jama.ama-assn.org/cgi/content/full/286/15/1897 doi:10.1001/jama.286.15.1897 